\title{
Rare diseases research in Europe: an overview based on data from the Orphanet database
}

\author{
Natalia Martin, Nicolas Doulet, Virginie Hivert, Ségolène Aymé* \\ From 5th European Conference on Rare Diseases (ECRD 2010) \\ Krakow, Poland. 13-15 May 2010
}

Orphanet compiles 6500 research projects. This information been analysed to identify areas in need of collaborative research projects and to target future calls for proposals. The analysis of the distribution of number of diseases by number of treatments in development showed that most RD have no more than 3 orphan designations, whereas 53 RD have over three orphan designations. Similar results were obtained when clinical trials, marketed drugs, patient registries and preclinical/epidemiological/ basic research were analysed. Some of the diseases which were over-represented upstream in the process of $R \& D$ (with a treatment on the market or drugs in development) are also well represented regarding ongoing research, like Cystic fibrosis, pulmonary arterial hypertension and some rare cancers. Diseases with a higher prevalence are anticipated to have more treatments in development: this assumption is not backed up by our data analysis. The best represented medical domain in terms of percentage of diseases with MA/OD is rare tumours, followed by Systemic and Rheumatologic diseases, Respiratory diseases, Immunological diseases, Metabolic diseases and Haematological diseases. It seems that the most mature fields keep on investing in research and are also the strongest ones regarding the products in development, and even in basic research for some of them. Other fields, however, like Neurology, seem to be essentially in development, since the percentage of diseases with MA is low compared to other domains and to the percentage of neurologic diseases with OD, clinical trials and research. The absence of orphan designations for some medical domains, like Cardiology, could be explained by the fact that the Cardiology rare diseases benefit from treatments already available for these diseases' common forms. This work was supported by the RareDiseasePlatform contract (RDPlatform), a three-year project which began in May

\footnotetext{
* Correspondence: segolene.ayme@inserm.fr

Orphanet, Plateforme Maladies Rares, 96 rue Didot, 75014 Paris, France
}

2008, financed by the European Union's Seventh Framework Programme (HEALTH-F2-2008-2012).

Published: 19 October 2010

doi:10.1186/1750-1172-5-S1-P5

Cite this article as: Martin et al:: Rare diseases research in Europe: an overview based on data from the Orphanet database. Orphanet Journal of Rare Diseases 2010 5(Suppl 1):P5.
Submit your next manuscript to BioMed Central and take full advantage of:

- Convenient online submission

- Thorough peer review

- No space constraints or color figure charges

- Immediate publication on acceptance

- Inclusion in PubMed, CAS, Scopus and Google Scholar

- Research which is freely available for redistribution

Submit your manuscript at www.biomedcentral.com/submit
C Biomed Central 